\title{
Performance Evaluation and Modification of Coconut Tree Climber
}

\author{
N. Sridhar ${ }^{1 *}$, A. Surendrakumar ${ }^{2}$ and C. Selvakumar ${ }^{3}$ \\ ${ }^{1}$ Farm Machinery and Power, AEC \&RI, Kumulur, Trichy- 621712 , \\ Tamil Nadu Agricultural University, India \\ ${ }^{2}$ Farm Machinery and Power, AMRC, TNAU, Coimbatore- 641003 , \\ Tamil Nadu Agricultural University, India \\ ${ }^{3}$ District Manager, Netafim Irrigation India Pvt. Ltd., India \\ *Corresponding author
}

A B S T R A C T

Keywords

Coconut harvesting, Modification of tree climber.

\section{Article Info}

Accepted:

10 October 2017

Available Online:

10 December 2017
In India, earlier days, skilled and experienced laborers' were engaged to climbing on coconut tree for harvesting nuts, crown cleaning and toddy tapping. But now a day's difficulty to get the service of skilled coconut climbers in time and their high wages are thus perceived as important constraints in the field of coconut cultivation. It was a challenge to the agricultural technology developers to fabricate a simple, safe and easy to use device for climbing coconut palms, which could even be operated by an unskilled person. Keeping in view the above facts, the present investigation on performance evaluation and modification of coconut tree climber was undertaken to develop safety unit for overcoming coconut harvesting constraint.

\section{Introduction}

Coconut (Cocos nucifera L.) is an important cash crop in India. India is the third largest producer of coconut in the world. Coconut is grown in an area of about 18.7 million ha with a productivity of 5718 nuts per hectare in India (National Horticulture Board, 2011). According to Parthasarathy et al., (2006) coconut is a perennial crop. The tree has a robust, cylindrical, vertical stem with a single growing point from where successive leaf production takes place producing a terminal crown. The tree crop can grow upto 20-30 meters in tall cultivars and $10-15$ meters in dwarf cultivars. Tall and dwarf are important varieties of coconuts. Flowering in tall cultivars starts in about 5-6 years after planting but in dwarf cultivars, it starts in third or fourth years. Annual growth of stem is by addition of scars with marks of leaf base as a result of the annual production of 12 to 14 leaves on the crown. The single coconut tree produces 12 to 14 leaves annually. Increment in stem height per year will range between $23 \mathrm{~cm}$ to $36 \mathrm{~cm}$. the growth a characteristic of coconut tree is shown in Table 1. 
In general, trained workers climb to harvest the coconuts from the tree without any safety device. The coconut trees are very tall and injuries associated with coconut tree climbing, particularly falling from coconut trees is common in coconut plantations in India. The workers employed for climbing coconut tree suffer musculoskeletal disorders than any other type of injury or illness. George et al., (2012) reported that a total of $35.5 \%$ (78 cases out of 220 climbers) fell down from coconut trees while doing their job. A $7.9 \%(19 / 240)$ of the tree climbers in the study area withdrew from their traditional profession and remained unemployed. Among them, only $5.3 \%$ (1/19) stopped climbing trees due to health problems and $94.7 \%$ $(18 / 19)$ withdrew because of casualties that happened during their occupation. Mohankumar et al., (2013) developed tree climbing device and evaluated based on ergonomical parameters and ergo refinements. The inclination of upper frame of climbing device is increased with respect to the horizontal, while moving towards the top of the tree. As a result, the centre of gravity of the user moves towards outside of the body making the operator feel insecure and unstable.

The upper frame of coconut tree climbing device was suitably modified to avoid downward inclination such that ergo refined device improves the safety and ease of operation. Morris (2002) developed a climbing tree stand having a first platform and a second platform having a base frame, a first arm and a second arm, a support arm, first and second illumination assemblies, and a blade attached to an upper bracket of the base frame. The first and second arms were pivotally attached to the base frame and were releasable engage able with the support arm. The support arm had a curved portion at an opposed distal end of the first arm and second illumination assembly was attached to a distal end of the second arm of each platform. The second platform included a foot support lifting bracket attached to its base frame. The foot support lifting bracket was comprised of rigid non flexible structure. Graham et al., (2003) developed an adjustable tree stand comprising of a seating section and a standing section, each having inclined attachment bars adjacent the section sides, and seating and standing section cables, each having first and second ends with handles at each of the ends. Each attachment bar had outer and inner faces with a plurality of spaced, aligned attachment holes extending between the faces, and a plurality of spaced, aligned latch holes alternating with the attachment holes. Each of the handles had a pair of flanged projections insert able into adjacent attachment holes in an attachment bar and a latch pin insert able into a latch hole between the adjacent holes.

Each projection was moveable from an insertion position to a locked position within a hole when the cable was tensioned, and was prevented by the latch pin from moving back to the insertion position when the cable was relaxed. Joseph (2006) developed a coconutclimbing device having two frames (left and right). Each frame was having flexible adjustable encircling iron rope mounted around a tree and tree gripping rubber pad. The two main frames were fitted on the tree side by side enabling the operator to lift the frames conveniently using the sliding member. Laborde (2006) developed a climbing tree stand apparatus with upper and lower platforms that were independently movable up the tree from under alternatively sitting and standing on one or the other of the platforms. There is no device available with safety features and easy climbing on coconut trees. Keeping the aforementioned facts in view, the simple device was fabricated with safe and easy to use device for climbing coconut palm, which could even be operated by an unskilled person. 


\section{Materials and Methods}

The modifying tree climbing device must ensure the following requirements. It should withstand enough loads exerted by climber, accommodate both male and female climber and provide effective gripping over a wide range of tree diameters and different the shape of the tree trunk.

\section{Conventional method}

In the conventional method, the two basic techniques used for climbing coconut trees are front foot technique and frog technique. However, these two techniques can be effectively handled by skilled person only. Rate of climbing a tree is dependence on the climbing experience based on the number of years and age and health condition of the persons. Conventional method of climbing causes series injuries for new as well as experienced tree climbers.

\section{Constrained observed during field study of conventional tree climber}

FIM model coconut tree climbing device having problem of high weight of lower part than upper part which gives more painful to lift the lower part during the climbing at the same time which reduce climber capacity to climb and get down from the tree. Removable gripping member made of straight square shaft mounted by gripping aid which is not properly hold instead of slid down during the climbing, because trunk diameter varies from bottom to top of the coconut tree. Similarly Kerala model coconut tree climbing device has flowing problems observed during the field study. It is not have seat arrangement so climber has to climb on tree in standing way only. During the climbing it gives fear to untrained male and female climber because it is not having any safety device to reduce fear during climbing on coconut tree.

\section{Modified coconut tree climber from exiting units}

Conventional coconut tree climber was modified to overcome above observed constrains during the field study. Modified coconut tree climber consists of lower and upper part as shown in Figure 1.

\section{Upper part of modified coconut tree climber}

The upper frame member is a tubular frame work consisting of a rigid base section and an adjustable tree gripping section consisting of a rigid base section and an adjustable tree gripping section. The rigid base section carries a seating arrangement for accommodating the user, front support rail, cross rear rail and side rails. The user can sit comfortably facing the tree and receive support from the cross rear rail and the side rails (Fig. 2).

The seat is a flexible sagging type made of rexin fabric attached through loops between the rear and front cross rails of the frame. The tree gripping section consists of gripping aids to engage it on three points on the circumference of the tree. The gripping aid is a rubber tubes folded on tubular square bar. The gripping section has three members which form a triangular throat that encompasses the upright coconut tree trunk, thereby permitting the upper frame member to be fixed to the tree.

One of the craved removable gripping members is attached to the extendable arm and the other two are attached in " $V$ ' shape to the front support bar of the seating frame. The spacing between the gripping members is adjustable with the help of extendable arm to suit the girth of the coconut tree. The overall dimensions and specifications of upper frame furnished in the Table 2 . 
Lower part of modified coconut tree climber

The device for climbing the tree has one frame. The main frame is made of $6 \mathrm{~mm}$ diameter mild steel rod. The frame comprises of flexible adjustable encircling iron rope of 8 $\mathrm{mm}$ diameter and length $58 \mathrm{~cm}$ mounted around a tree and tree gripping semi-circular pad made of worn out tyre rubber pad fitted against a tree trunk. One end of the iron rope is attached to rubber pad and another end placed on center of the foot rest to changing rope length according to girth of the tree (Fig. $3)$.

At the center of foot rest locking device is welded which help to lock the ropes. The main frames having the foot rest comprise of a safety strap to prevent accidental slip during engagement with the climber's feet while ascending and descending the tree and handle is provided for easy lifting. The main frames are fitted on the tree center enabling the operator to lift the frames conveniently. The overall dimensions and specifications of upper frame furnished in the Table 3.

\section{Working of tree climber}

Before climbing the tree, the climber (operator) need to fix the climbing device (both bottom and upper unit) to the tree with the help of the removal gripping aid and iron rope. After fixing the unit to the coconut tree in order, the climber sit on upper unit (sitting unit) and then keeping both legs in the footrest provided on bottom unit (standing unit). Initially upper unit of the device must be lifted by hand to about 30 to $40 \mathrm{~cm}$ and then lifting the bottom unit by loose the iron rope which is locked with foot rest. The operation will be repeated to reach the required height. For climbing down, the reverse operation will be followed, i.e. release the wire rope of the bottom unit by lifting the footrest followed by climber bringing down the upper unit by $30-40 \mathrm{~cm}$ and then puts the body weight on both footrests.

\section{Results and Discussion}

The developed equipment was evaluated in the field by unskilled operators. Tall varieties of coconut tree were used to determine the capacity of the equipments. The capacity of the equipment was determined by calculating number of coconut tree climbed in specific period of time by unskilled operators (Table 4). The formula is used for determining the capacity of the equipment is given below

Capacity $=$ Number of coconut tree climbed / time taken

Table.1 Growth characteristics of coconut tree

\begin{tabular}{|c|c|c|c|}
\hline Parameter & Tall & Dwarf & Hybrid \\
\hline Total leaves (Nos.) & 35 & 31 & 32 \\
\hline Leaf productions years $^{-1}$ (Nos.) & 12 & 10 & 10 \\
\hline Stem growth year $^{-1}$ (cm) & 36 & 25 & 23 \\
\hline
\end{tabular}


Table.2 Overall dimensions and specifications of upper frame

\begin{tabular}{|c|c|c|c|}
\hline S.No. & Particulars & No of quantity & Dimensions \\
\hline 1 & MS-Square pipe & - & $25 \times 25 \times 3 \mathrm{~mm}$ \\
\hline \multirow[t]{2}{*}{2} & Length of square pipe & 2 & $90 \mathrm{~cm}$ \\
\hline & & 3 & $50 \mathrm{~cm}$ \\
\hline 3 & $\begin{array}{l}\text { For making V- shape Required } \\
\text { square pipe }\end{array}$ & 2 & $26 \mathrm{~cm}$ \\
\hline \multirow[t]{3}{*}{4} & Hollow pipe - Thickness & \multirow[t]{3}{*}{1} & $3 \mathrm{~mm}$ \\
\hline & Hollow pipe length & & $50 \mathrm{~cm}$ \\
\hline & $\begin{array}{l}\text { Bending of hollow pipe made } \\
\text { semi -circle }\end{array}$ & & $180 \mathrm{deg}$ \\
\hline \multirow[t]{2}{*}{5} & Griping aid (Rubber tubes) & & $2 \mathrm{~mm}$ thickness \\
\hline & Overall dimension modified unit & & $90 \times 50 \mathrm{~cm}$ \\
\hline
\end{tabular}

Table.3 Overall dimensions and specifications of upper frame

\begin{tabular}{|l|l|c|c|}
\hline S.No & Particulars & Quantity & Dimensions \\
\hline 1 & MS-rod & & $6 \mathrm{~mm}$ diameter \\
\hline \multirow{4}{*}{} & Length of rod for making main portion & 3 & $40 \mathrm{~cm}$ \\
\cline { 2 - 4 } & Length of rod for making Handle & 1 & $140 \mathrm{~cm}$ \\
\cline { 2 - 4 } & Bottom gripping aid & 1 & $28 \mathrm{~cm}$ \\
\cline { 2 - 4 } & Bottom gripping aid bent for made semi -circular & & $180 \mathrm{deg}$ \\
\hline 2 & Length of one inch square pipe for foot rest & 1 & $58 \mathrm{~cm}$ \\
\hline 3 & Iron rope length & 2 & $45 \mathrm{~cm}$ \\
\hline & Over all dimension of main frame & & $58 \times 43 \mathrm{~cm}$ \\
\hline
\end{tabular}

Table.4 Capacity of the equipment to climb coconut tree by unskilled operators

\begin{tabular}{|c|c|c|c|c|c|c|c|}
\hline S. No & Details & \multicolumn{6}{|c|}{ Trail Results } \\
\hline 1 & Place of Trail & \multicolumn{6}{|c|}{ Bai Garden, AEC \& RI -Kumulur } \\
\hline 3 & & $\begin{array}{l}\text { Operator } \\
1\end{array}$ & $\begin{array}{l}\text { Operator } \\
2\end{array}$ & $\begin{array}{l}\text { Operator } \\
3\end{array}$ & $\begin{array}{l}\text { Operator } \\
4\end{array}$ & $\begin{array}{l}\text { Operator } \\
5\end{array}$ & $\begin{array}{l}\text { Operato } \\
\text { r } 6\end{array}$ \\
\hline 4 & Age (in Year) & 20 & 21 & 20 & 20 & 20 & 20 \\
\hline 5 & Weight of the subject & 49 & 53 & 48 & 47 & 42 & 45 \\
\hline 6 & Height of the subject & 178 & 166 & 178 & 167 & 164 & 150 \\
\hline 7 & $\begin{array}{l}\text { Time for climbing the tree, } \\
\text { (seconds) }\end{array}$ & 69 & 59 & 72 & 60 & 87 & 91 \\
\hline 8 & $\begin{array}{l}\text { Time for harvesting nuts, } \\
\text { (Seconds) }\end{array}$ & 123 & 114 & 130 & 121 & 150 & 156 \\
\hline 9 & $\begin{array}{l}\text { Time for climbing down, } \\
\text { (Seconds) }\end{array}$ & 71 & 62 & 71 & 64 & 91 & 94 \\
\hline 10 & $\begin{array}{l}\text { Total time consumed, } \\
\text { (seconds) }\end{array}$ & 263 & 235 & 273 & 245 & 328 & 341 \\
\hline 11 & Harvesting kg/ hours & 56 & 58 & 53 & 60 & 46 & 41 \\
\hline
\end{tabular}


Fig.1 Modified coconut tree climber

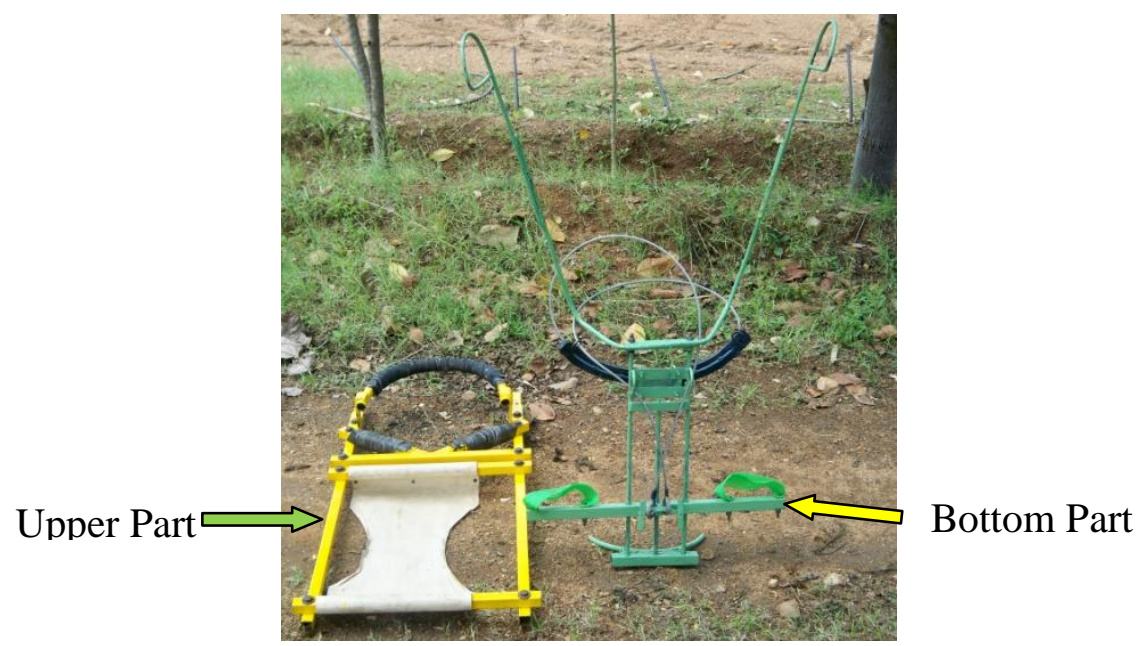

Fig.2 Upper part of modified coconut tree climber

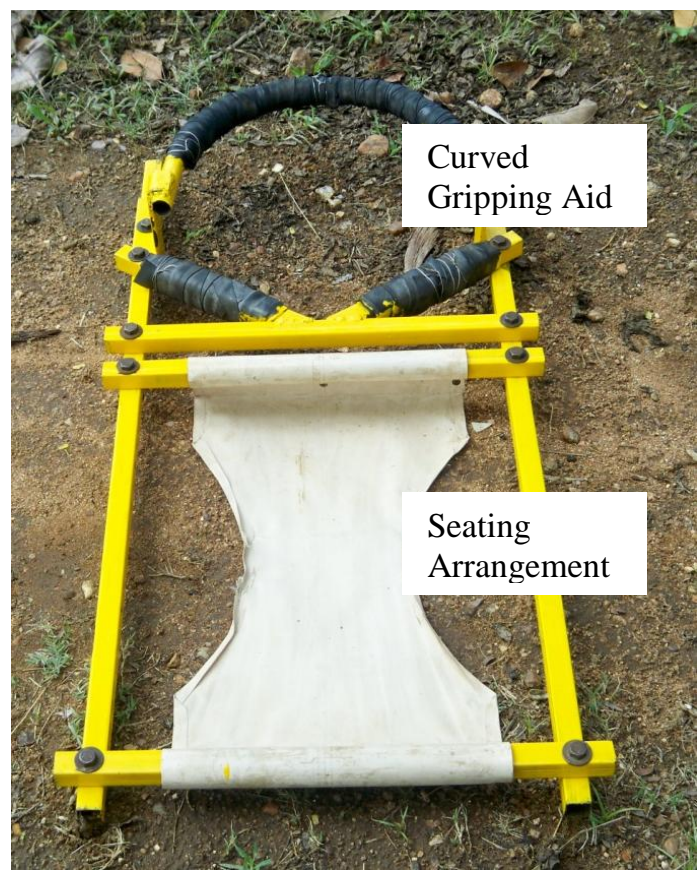

The capacity of the machine was found to be 8 tree /hours. From the above fact, it can be observed that time taken for climbing and harvesting a single tree is about 7.5 minutes

The climbing of coconut tree with manually operated coconut tree climber was found to be easier for both male and female without the
Fig.3 Lower part of modified coconut tree climber

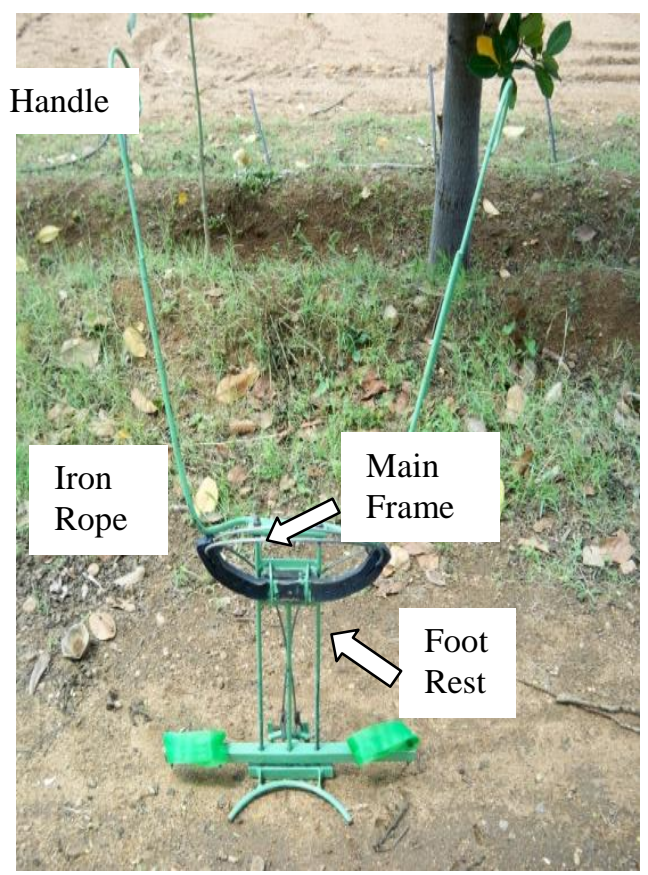

need of any skilled labour. Based on the evaluation following results were obtained. The time taken for climbing single tree was 65 seconds (unskilled operator) whereas the time taken for climbs it manually was only 30 seconds (skilled operator). Even though, there is no saving in time but the climbing operation can be done by anybody without 
any special skills and without causing any damage to the operator with full safety. The cost of the device is low compared to other models and can be used by any households having one or more coconut trees.

\section{References}

George M, Bincy R, Muddanna S, Kumar A, Suvarna N, D'Souza JS.2012. "Health of Coconut Tree Climbers of Rural Southern India" Medical Emergencies, Body Mass Index and occupational Marks: A Quantitative and Survey Study. J. Clin. Diagn. Res. 6(1):57-60.

Graham Jr., Thomas E, Graham Sr., Christopher L. 2003. Adjustable tree stand, US Patent. 6668976B2.
Joseph.2006. Making man reach the moon: Top of tree, honey bee Vol 17(1) \& (2). pp.14.

Laborde, J.2006.Hunters climbing tree stand and method of use, US patent. 6986404B1.

Mohankumar P., D. Anantha Krishnan and K. Kathirvel, "Development of ergo refined coconut tree climbing device", African Journal of Agricultural Research, Volume 8, November 2013.

Morris, 2002. Climbing tree stand, US patent6345690B1.

Parthasarathy, V.A., P.K. Chattopadhyay and T.K. Bose (eds). 2006. Plantation Crops. Vol.2. published in 2 volumes and p.p.519 by Naya Udyou, Kolkatta.

\section{How to cite this article:}

Sridhar, N., A. Surendrakumar and Selvakumar, C. 2017. Performance Evaluation and Modification of Coconut Tree Climber. Int.J.Curr.Microbiol.App.Sci. 6(12): 1195-1201. doi: https://doi.org/10.20546/ijcmas.2017.612.135 